\title{
Enrichment of coastal zooplankton communities by drifting zooplankton patches from the Kuroshio front
}

\author{
Mikio Noda ${ }^{1, *}$, Itaru Ikeda ${ }^{1}$, Shunshiroh Ueno ${ }^{1}$, Hiroaki Hashimoto ${ }^{2}$, Kenji Gushima ${ }^{2}$ \\ ${ }^{1}$ Department of Applied Aquabiology, National Fisheries University, Nagata-Honmachi Shimonoseki 759-6595, Japan \\ ${ }^{2}$ Faculty of Applied Biological Science, Hiroshima University, Higashi-Hiroshima 739-0046, Japan
}

\begin{abstract}
The community structure of copepods and chaetognaths in a Kuroshio-associated coastal area in the south of Japan was investigated in order to consider what forces (biological and/or physical) potentially produce drift zooplankton patches, an essential prey resource of planktivorous reef fish at the study site. On the basis of bimonthly samples of the patches and routine collections from October 1987 to August 1988, we compared the community structures within and outside the patches. The patches consisted largely of a great variety of copepods and chaetognaths and exhibited high prey densities compared with routine samples. Within months, similarity values between patches and routine samples were relatively low, as were those between patches and the cumulative routine samples. In contrast, similarity values of patches compared with one another within months were high, as were those among months, suggesting that the patches depended on a common water mass retained through the entire year. Useful indicator species of the Kuroshio water and oceanic species dominated the patches in percentages and species numbers, while neritic species dominated routine samples. The neritic species composition of the patches was characterized by only 2 copepod species, Oncaea media and Microsetella norvegica, whereas the routine samples were numerically balanced by various neritic species. These results show that the zooplankton community structure in the patches is dominated by species which are usually found in the Kuroshio front formed in open sea environments. It may play an important role in supplying reef-dwelling planktivores with their main prey resource.
\end{abstract}

KEY WORDS: Front - Kuroshio · Patch · Aggregation · Copepod · Chaetognath · Planktivores

\section{INTRODUCTION}

It has been well documented that physical, hydrodynamic processes such as eddies, fronts, and upwellings play an important role in the heterogeneous distribution of pelagic organisms and biological production regulated by temperature, light and nutrients in open ocean environments (e.g. Uda \& Ishino 1958, Yoder et al. 1981, 1983, Yoder 1983). Similar phenomena have also been reported in the warm Kuroshio Current (e.g. Yamamoto et al. 1981, Kuroda 1986, Yamamoto \& Nishizawa 1986, Yamamoto 1989, Terazaki 1992. Nishikawa et al. 1995, Nakata 1997). It flows along the south coast of the Japanese islands and turns eastward around $36^{\circ} \mathrm{N}$ into the Kuroshio Extension. Often formed at the boundary between the southern high

\footnotetext{
•E-mail: nodam@fish-u.ac.jp
}

temperature and salinity Kuroshio water and the northern low temperature and salinity neritic water, the Kuroshio front has been considered to retain high productivity because of the accumulation of pelagic organisms, entrainment of coastal water, and nutrient supply associated with upwelling around the front (Uda 1938, Yamamoto et al, 1988). In addition, the front around the Tokara Strait off the south coast of Kyushu has recently been demonstrated to migrate over about $150 \mathrm{~km}$ from south to north between Cape Satamisaki and Nakanoshima Island within a period of 20 to $30 \mathrm{~d}$ (Nagata \& Takeshita 1985, Akiyama \& Ameya 1991). Thus, warm water from the Kuroshio current aften intrudes into the south coastal zone of Kyushu. These intrusions strongly affect biological processes, such as fish migration and behavior, eggs and larval transport, and fishing conditions, in coastal areas (Hanaoka 1972, Takeshita 1983, Miyaji 1991, Sugimoto \& Tameishi 1992). However, the influence of such short-term fluc- 
tuations on zooplankton fauna in coastal areas remains unclear. These short-term intrusions may be a major influence on the prey availability of reef-dwelling planktivores because they may cause changes or modifications in coastal zooplankton communities. Thus, they are of great importance to the understanding of the trophic relations of reef-dwelling planktivores.

Noda et al. (1992) have shown that at Kuchinoerabu Island north of the Tokara Strait zooplankton patches are a major source of food for planktivorous reef fishes such as the pomacentrid fish Chromis chrysurus because they occur after long intervals of low prey densities and include numerous and various large prey. Noda et al. (1992) have demonstrated the importance of understanding the supply mechanism of zooplankton patches in relation to hydrographic and/or biological forces, either short-term only or seasonal processes, in order to elucidate the pattern of the occurrence of the patches and the regularity of occurrence of large prey, either their ordinary occurrence based on systematic causes or as a result of occasional causes. These help explain the adaptive responses of planktivorous fish in terms of efficient utilization of such patches.

We compared zooplankton community structures within and outside rich zooplankton patches, namely, zooplankton patch samples and routine zooplankton in a coastal region in order to examine the potential biological and/or physical forces that produce them. The objectives of this study were 2 -fold: first, to show that zooplankton patches derive from the Kuroshio front. To accomplish this, the 2 kinds of samples were compared in degree of similarity and seasonal patterns of species composition. Second, the importance of the Kuroshio front in supporting planktivorous fish communities on coastal reefs was inferred.

\section{MATERIALS AND METHODS}

The present investigation summarizes 100 surface zooplankton samples collected every 2 mo from October 1987 to August 1988 in the inshore study site of Nishiura Bay and Honmura Bay (within 100 m seaward from each shore, 2 to $8 \mathrm{~m}$ deep), Kuchinoerabu Island $\left(30^{\circ} 28^{\prime} \mathrm{N}, 130^{\circ} 12^{\prime} \mathrm{E}\right), 12 \mathrm{~km}$ northwest of Yaku Island, Japan (Fig. 1)

All of the samples were collected with a snorkeling, diver-operated, conical net $(30 \mathrm{~cm}$ diameter, $60 \mathrm{~cm}$ length, $0.1 \mathrm{~mm}$ mesh size) in the surface layer Zooplankton patch samples were collected as the conical

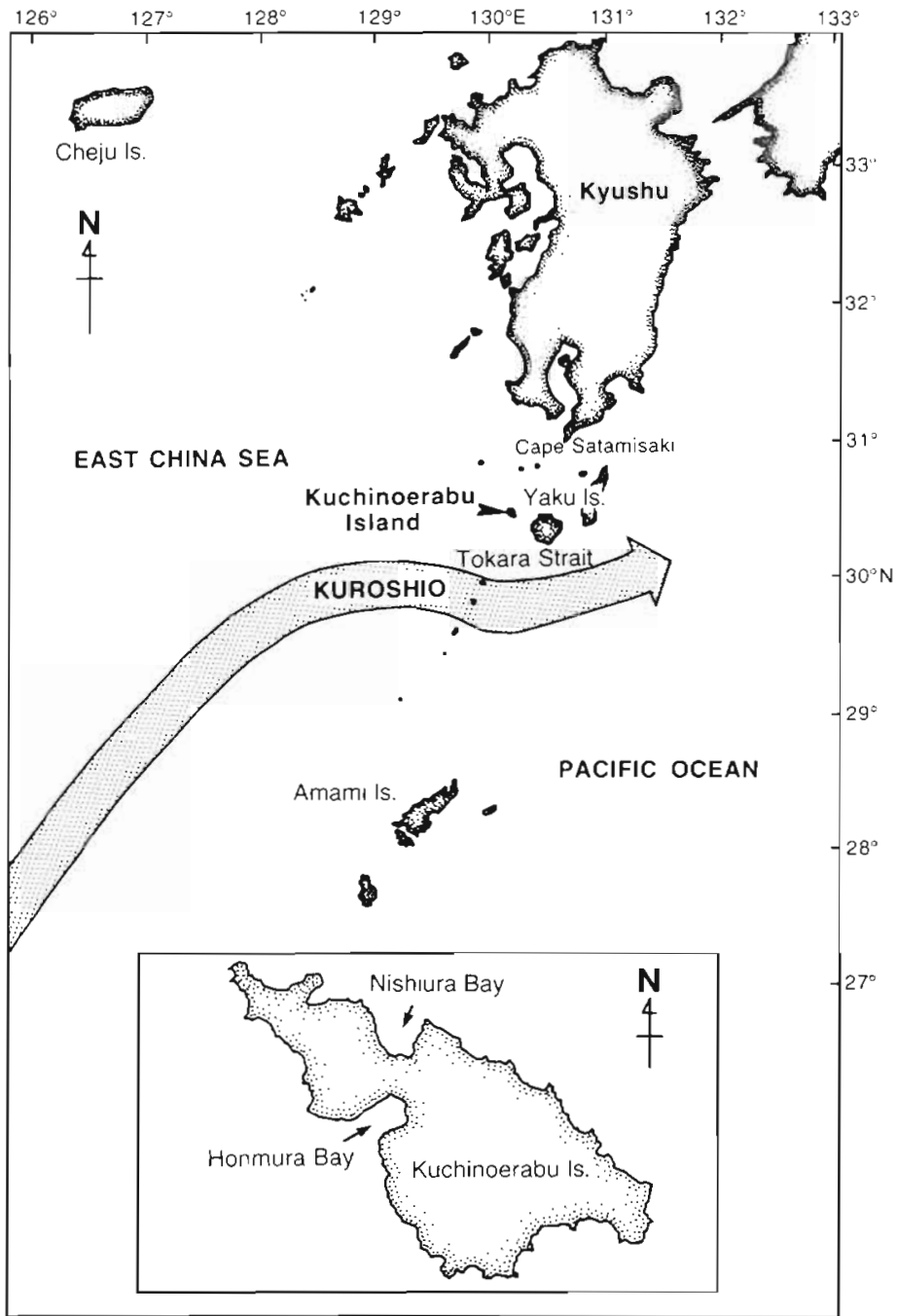

Fig. 1. Location of Kuchinoerabu Island and the general configuration of a representative current of the Kuroshio stream

net was quickly swept through the surface layer by a diver who held the opening ring with both hands. Routine samples were collected by strongly pushing the net through a diver's fin thrust along a given line. This change in method was necessitated because the resident background zooplankton were widely distributed in contrast to the patches. Net filtration was calculated with a small flowmeter fitted across the opening, and the volume of water filtered per sample was less vari-

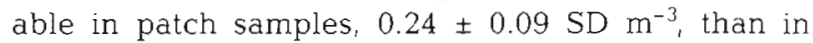
routine samples, $0.50 \pm 0.11 \mathrm{SD} \mathrm{m}^{-3}$. To reduce inconvenience in handling the plankton collected, polyethylene bottles $(50 \mathrm{ml})$ with a draining window $(0.1 \mathrm{~mm}$ meshj covered by a broad rubber band were screwed on the end of the net. This method permitted the snorkeling observer to handle the collected plankton easily and immediately preserve the sample in a $5 \%$ buffered formalin solution. This also prevented the loss 
of zooplankton to predatory zooplankters. Divers have often used such nets with very small openings to catch zooplankton (e.g. Ueda et al. 1983, Ohtsuka et al. 1995), and this sampling system was effective previously when we investigated zooplankton abundance in relation to the foraging ecology of planktivorous reef fishes (Noda et al. 1990, 1992, 1996).

In this case, sampling was concentrated within and around an observation area $\left(22663 \mathrm{~m}^{2}\right)$ of a local population of planktivorous reef fish Chromis chrysurus in which patterns of prey searching behavior were investigated by Noda et al. (1994) in the Nishiura Bay site. The observation area, corresponding nearly to the home range of its local population, had previously been mapped in detail, so zooplankton sampling positions were easily identified by the snorkeling diver. In spring and winter, sampling was also conducted in the Honmura Bay study site because of weather-related constraints and was positioned on the basis of topographical clues from the sea bottom so as to include locations where adult $C$. chrysurus were likely to aggregate. The ecology of $C$. chrysurus has been described in detail by Noda et al. $(1992,1994)$.

Zooplankton samples were collected by 2 procedures. With the first, zooplankton patch samples were collected at the Nishiura Bay site or the Honmura Bay site during daylight. Aggregating zooplankton was sought by snorkeling surveys for several hours per day. Densely aggregated zooplankton could be clearly recognized with the naked eye, and sometimes a snorkeling observer met a huge mosaic of zooplankton aggregations ranging from tens of meters to over a hundred meters in size. Aggregations that included a large number of copepods and chaetognaths were collected. With the second method, routine samples were collected at 2 stations in the Nishiura Bay site (ca $100 \mathrm{~m}$ seaward from the shore, ca $8 \mathrm{~m}$ deep, around the observation area of the local population of Chromis chrysurus) or at a station in the Honmura Bay site (ca $60 \mathrm{~m}$ seaward from the shore, ca $5 \mathrm{~m}$ deep) on a total of 4 to $10 \mathrm{~d}$ each month as successively as possible, except for breaks due to bad weather. The sampling was performed as the observer swam through the surface layer along $30 \mathrm{~m}$ lines fixed in the bottom between 11:00 and 12:00 h. The details of collection data are indicated in Table 1.

All samples were split 1 to 3 times, depending on the amount of plankton, with a miniature edition of a Motoda plankton splitter in the laboratory (Motoda 1959). Only adult copepods and chaetognaths were identified by species under a binocular microscope; and each species was counted, because the 2 taxa were known to be the most useful biological indices of environmental conditions in various waters, and they dominated zooplankton abundance numerically (Yamazi 1956, Motoda \& Marumo 1963, Terazaki 1990, 1997, Ohtsuka \& Ueda 1997). The body length of copepods and chaetognaths collected was measured to the nearest $0.1 \mathrm{~mm}$. Identification and classification of copepods were mainly based on Chen \& Zhang (1965, 1974), Chen \& Shen (1974) and Chen et al. (1974). Those of chaetognaths were based on Alvariño (1967).

Copepods and chaetognaths were sorted by species, and their respective numbers were counted. The community structures of copepods and chaetognaths were compared by numerical densities between routine samples and patch samples by using the similarity index $\alpha$ (Pianka 1973). The degree of overlap between communities $x$ and $y\left(\alpha_{x, y}\right)$ was calculated as:

$$
\alpha_{x, y}=\frac{\sum_{i=1}^{n} p_{x i} p_{y,}}{\sqrt{\sum_{i=1}^{n}\left(p_{x i}\right)^{2} \cdot \sqrt{\sum_{i=1}^{n}\left(p_{y i}\right)^{2}}}}
$$

where $p_{x i}$ is the ratio of the number of individuals of each copepod or chaetognath species $i$ to the total number of copepod and chaetognath individuals in community $x$ (similarly for $y$ ). This index ranges from 0 (no overlap) to 1 (complete overlap).

The community structures of copepods and chaetognaths were compared according to the densities of prey-sized individuals utilized by the planktivorous fish Chromis chrysurus, that is, $>0.8 \mathrm{~mm}$ in body length for copepods and $>4.0 \mathrm{~mm}$ in body length for chaetognaths (Noda et al. 1992). This size distinction was applied because the community structures were investigated in relation to food resource availability of reef-dwelling planktivores. 


\section{RESULTS}

\section{Prey densities and similarities between samples}

Whereas routine samples ranged from 0 to 7844 copepods and chaetognaths $\mathrm{m}^{-3}$ in their density of preysized individuals (hereafter referred to as prey density), patches ranged from 13087 to 77614 copepods and chaetognaths $\mathrm{m}^{-3}$. The maximum prey density of patches was 1 order of magnitude higher than that of routine samples.

The degrees of similarity between patches and routine samples were compared within months according to 4 classes of prey density range: $<1000,1000-2000,>2000 \mathrm{~m}^{-3}$, and patches (Fig. 2b). The degrees of similarity between patches and $<1000 \mathrm{~m}^{-3}$ were extremely low $(0.03$ to 0.21 on average) in each month except April, as were the similarities between patches and the cumulative species composition of routine samples of $<1000 \mathrm{~m}^{-3}(0.03$ to 0.55 on average), despite the fact that samples collected in the same month were compared. In contrast, the patches themselves showed a remarkably similar species composition to one another $(0.63$ to 0.92 on average) and also tended to increase in similarity in accordance with 3 classes of prey density ranges of routine samples. As an exception, the similarities in April were high overall, irrespective of prey density ranges of routine samples; but a detailed comparison of species compositions between patches and several samples of $<1000 \mathrm{~m}^{-3}$, indicating high similarities, suggested that the exception resulted from occasional samplings of copepods and chaetognaths derived from patches. Thus, it was clear that within each month patches originated not in the coastal waters involving zooplankton communities of low prey densities but rather in the same water mass imported from offshore. Furthermore, the lack of similarities between patches and the cumulative species composition of routine samples also indicate a process of dispersion of prey-sized copepods and chaetognaths included in the routine samples; that is, such prey appear to be dispersed into the coastal waters through the patches.

The degrees of similarity in patches were compared among months through the entire year (Fig. 2a). The similarities were, on the whole, high in all seasons by comparison with the result of routine samples versus patches within months although, in general, season is an influential factor. Furthermore, the ranges of variation were compared between 2 categories among months for patches versus patches and within months for patches versus routine samples (Table 2 ). The range of similarities in patches among months was significantly smaller than that within months except April. Consequently, most likely, the patches stemmed from a zooplankton community in a water mass retained through the entire year.
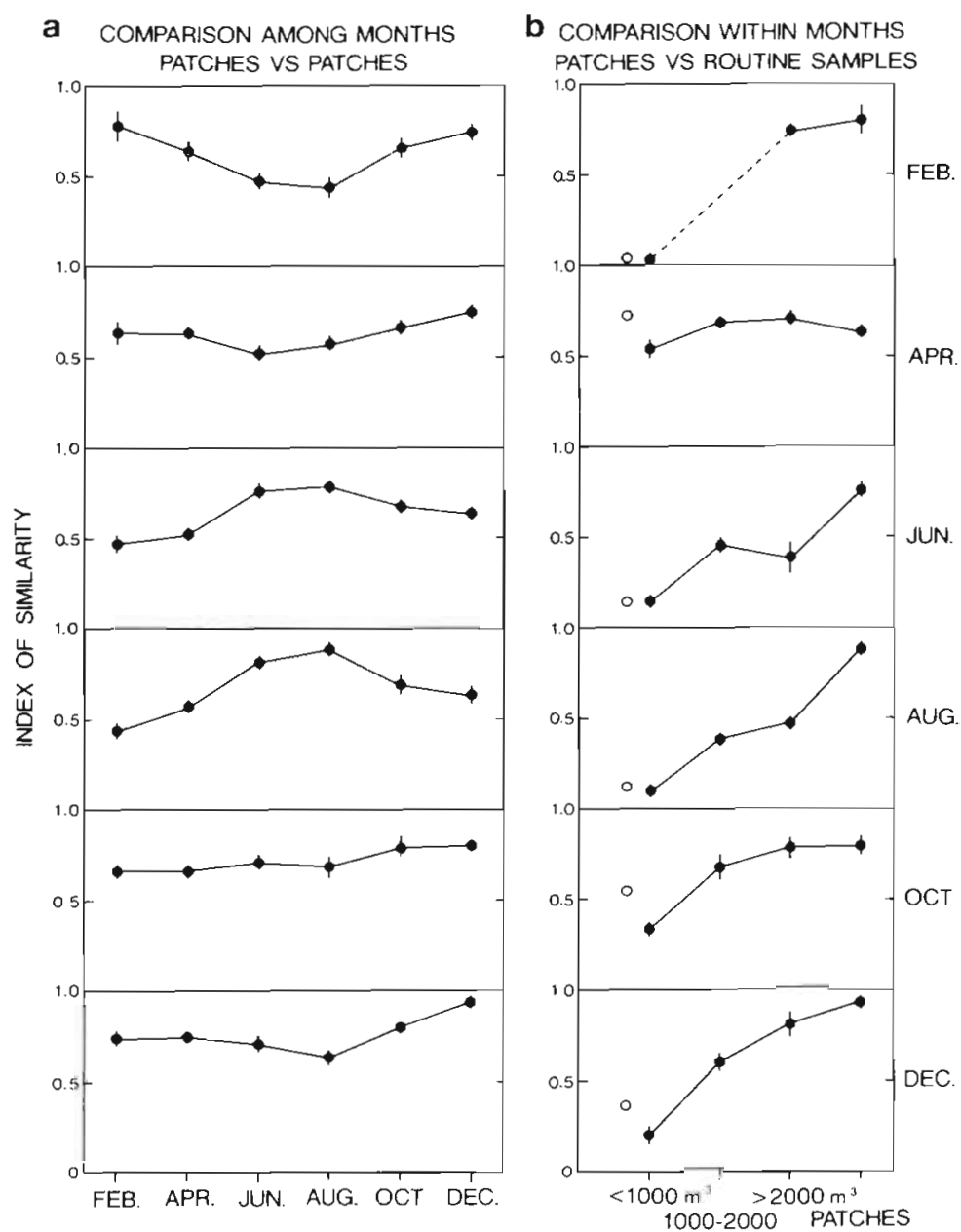

Fig. 2. Comparison of similarity indices between routine zooplankton samples (assigned to 3 classes based on prey densities of planktivorous fish for copepods and chaetognaths) and patch samples in species composition of copepods and chaetognaths. Pianka's index $\alpha$ (see the text) is applied to the analysis of the degrees of similanty. ( Values of index $\alpha$, indicating mean values $_{i}(0)$ values based on the cumulative species composition of samples of $<1000 \mathrm{~m}^{-3}$ in prey density of planktivorous fish. Vertical bars represent $1 \mathrm{SE}$. The panels in (a) indicate similarities among patches and compare those indices among 6 mo in which patches were sampled. The panels in (b) indicate similarities between patches and all the samples divided into 4 classes of prey density range within 6 mo 
Table 2. Comparison of ranges of variation of similarities represented by variance between 2 categories among months for patches versus patches and within months for patches versus routine samples, tested with a Mann-Whitney U-test. $\cdot p<0.01$; ns: not significant

\begin{tabular}{|lccc|}
\hline Category & \multicolumn{2}{c}{$\begin{array}{c}\text { Variances of } \\
\text { similarity indices } \\
\text { Mean }\end{array}$} & $\begin{array}{c}\text { No. of data } \\
\text { examined }\end{array}$ \\
\hline Among months & 18.23 & $(1.65)$ & 18 \\
Within months & & & \\
February & $51.57^{\circ}$ & $(1.69)$ & 3 \\
April & $27.23 \mathrm{~ns}(6.71)$ & 3 \\
June & $112.07^{\circ}$ & $(3.16)$ & 3 \\
August & $131.77^{\circ}$ & $(20.61)$ & 3 \\
October & $65.96^{\circ}$ & $(1.20)$ & 3 \\
December & $73.51^{\circ}$ & $(3.53)$ & 3 \\
\hline
\end{tabular}

\section{Characteristics of species composition in patches}

The relationship between prey densities and number of species for copepods and chaetognaths in routine samples and patches is indicated in Fig. 3. The number of species increased with prey densities, and any patch comprised a great number of species by comparison with routine samples of low prey densities.

A total of 126 species of copepods and 13 species of chaetognaths were identified in all the samples. They are listed in Table 3 and assigned to the following 3 categories in relation to indicators of water conditions on the basis of 22 literature records (Yamazi 1956, Honjo et al. 1957, Furuhashi 1961, Motoda \& Marumo 1963, Hirota 1964, 1968, 1969a, b, Chen \& Zhang 1965.
1974, Chen et al. 1974, Chen \& Shen 1974, Hirota \& Hara 1975, Kuroda 1977, Kidachi \& Ito 1979, Ueda 1980, 1982, 1991, Hiromi 1981, Kidachi et al. 1983, Nishida 1985, Koga 1986): Kuroshio species (32 species) were regarded as useful indicators of the Kuroshio water and were recorded widely in collections from the Kuroshio current. Oceanic species (89 species) were distributed principally in oceanic and/or open-neritic waters, except Kuroshio species. Neritic species (18 species) were abundant in embayment waters or were distributed throughout embayment and neritic waters.

The percentage composition of individuals and number of species in each category were compared between patches and in 3 classes of routine samples (Fig. 4). Those values were expressed, not as averages of the whole of the samples, but as those of samples lumped together each month, that is, 6 sampling months, so we avoided a bias relative to sample sizes each month. The percentage of Kuroshio species increased with prey density and exhibited the highest value in the patches. Oceanic species remained on almost the same level. In contrast, neritic species comprised a large proportion of the total number in low prey density ranges, but with an increase in prey density these were reduced proportionately. The numbers of Kuroshio and oceanic species increased with prey density while the neritic species remained on almost the same level. Hence, it was clear that patches originated from the Kuroshio current.

On the other hand, neritic species were detected in the patches themselves as well as in the routine samples. This appears to be an incompatible fact, if the
Fig. 3. Relationship between prey densities of planktivorous fish and the total number of copepod and chaetognath species found in zooplankton samples. (•) Routine zooplankton samples, (o) patch samples; $\mathrm{N}$ : number of samples examined. Note log scale

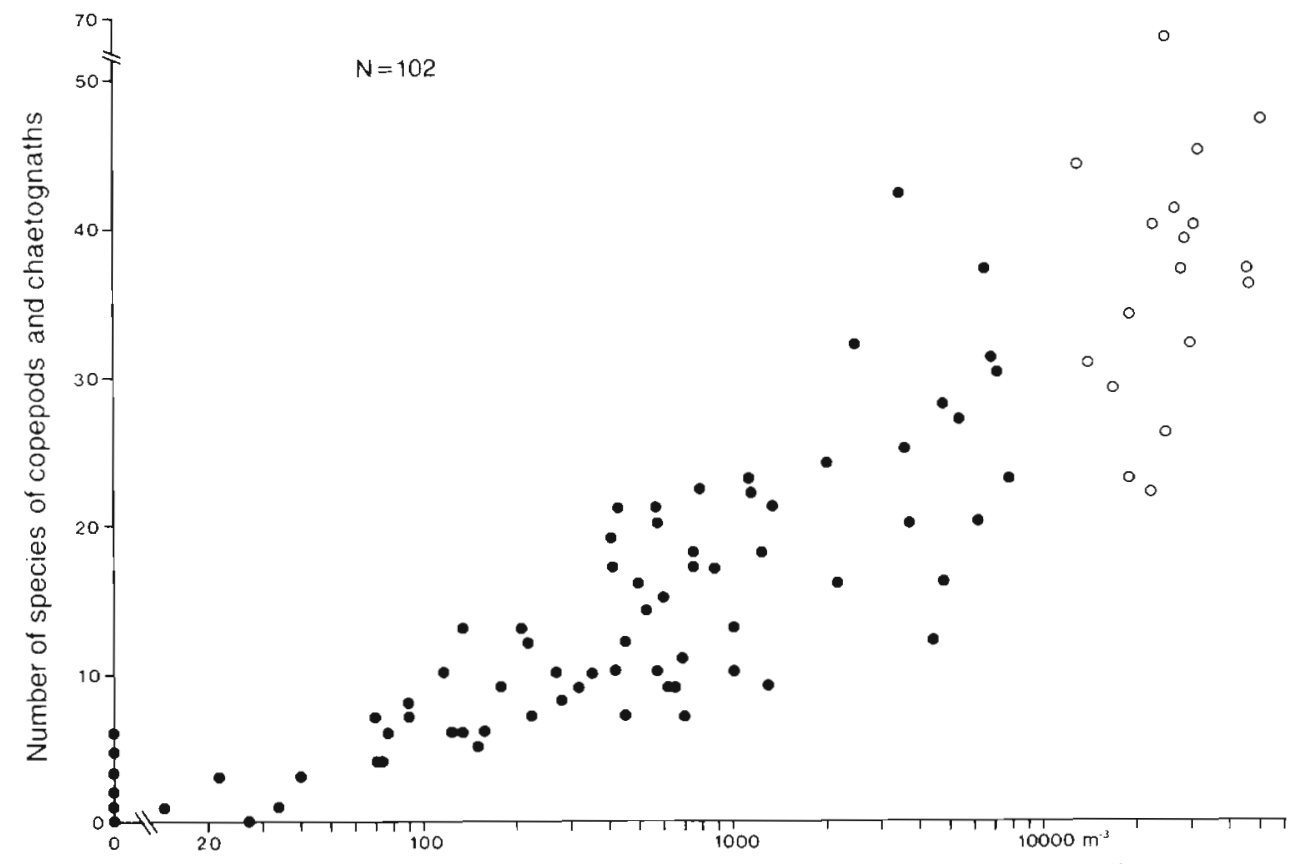

Prey densities of planktivorous fish for copepods and chaetognaths 
Table 3. List of copepod and chaetognath species collected at Kuchinoerabu Island in southern Japan from October 1987 to August 1988. The collected species were assigned to 3 categories on the basis of water indices conditions and 22 literature records (see the text)

\begin{tabular}{|c|c|c|c|}
\hline Kuroshio species & \multicolumn{2}{|c|}{ Oceanic species } & Neritic species \\
\hline Copepoda & \multicolumn{2}{|c|}{ Copepoda } & Copepoda \\
\hline Calanoida & Calanoida & Cyclopoida & Calanoida \\
\hline Acartia negligens & Acartia danae & Copilia quadrata & Acartia pacifica \\
\hline Candacia bipinnata & Acrocalanus gracilis & Corycaeus agilis & Calanus sinicus \\
\hline Clausocalanus furcatus & A. gibber & C asiaticus & Paracalanus crassirostris \\
\hline Eucalanus attenuatus & A. longicornis & C. carinata & P. elegans \\
\hline E. pileatus & A. monachus & C. catus & P. nudus \\
\hline E. subtenuis & Calocalanus contractus & C. concinnus & P. parvus \\
\hline E. subcrassus & C. gracilis & C. dahli & Cyclopoida \\
\hline Euchaeta marina & C. monospinus & C. erythraeus & Corycaeus affinis \\
\hline E. Iongicornis & C. pavo & C. flaccus & C. andrewsi \\
\hline Lucicutia flavicornis & C. pavoninus & C. gibbulus & Oithona attenuata \\
\hline Mecynocera clausi & C. plumulosus & C. lautus & O. brevicornis \\
\hline Neocalanus gracilis & C. styliremis & C. longicaudis & O. nana \\
\hline N. tenuicornis & Candacia aethiopica & C. longistylis & O. rigida \\
\hline Nannocalanus minor & C. catula & C. pacificus & O. simplex \\
\hline Paracalanus aculeatus & C. curta & C. pumilus & Oncaea media \\
\hline Pleuromamma gracilis & C. discaudata & C. rostratus & Harpacticoida \\
\hline $\begin{array}{l}\text { Rhincalanus cornutus } \\
\text { R. nasutus }\end{array}$ & C. pachydactyla & C. robustus & Euterpina acutifrons \\
\hline $\begin{array}{l}\text { R. nasutus } \\
\text { Scolecithrix danae }\end{array}$ & C. truncata & C. speciosus & Microsetella norvegica \\
\hline $\begin{array}{l}\text { Scolecithrix danae } \\
\text { Undinula darwinii }\end{array}$ & $\begin{array}{l}\text { Canthocalanus pauper } \\
\text { Centropages calaninus }\end{array}$ & $\begin{array}{l}\text { C. subtilis } \\
\text { C. viretus }\end{array}$ & M. rosea \\
\hline U. vulgaris & C. longicornis & Lubbockia squillimana & Chaetognatha \\
\hline Cyclopoida & C. gracilis & Oithona fallax & Sagitta nagae \\
\hline Copilia mirabilis & Clausocalanus arcuicornis & O. setigera & \\
\hline Oithona plumifera & C. farrani & O. tenuis & \\
\hline Oncaea venusta & C. paululus & O. vivida & \\
\hline & C. pergens & Oncaea clevei & \\
\hline & Euaetideus acutus & $O$. conifera & \\
\hline Krohnitta pacifica & Eucalanus mucronatus & O. mediterranea & \\
\hline Pterosagitta draco & E. crassus & O. minuta & \\
\hline Sagitta enflata & Euchaeta concinna & Pachysoma punctatum & \\
\hline S. hexaptera & E. plana & Sapphirina angusta & \\
\hline S. minima & E. wolfendeni & S. gastrica & \\
\hline S. pseudoserratodentata & Euchirella areata & S. gemma & \\
\hline S. pacifica & Paracalanus gracilis & S. metallina & \\
\hline \multirow{9}{*}{ S. regularis } & P. nanus & S. nigromaculata & \\
\hline & Pontellina plumata & S. opalina & \\
\hline & Pleuromamma robusta & S. ovatolanceolata & \\
\hline & Scolecithricella bradyi & S. sinuicauda & \\
\hline & Scolecithrix nicobarica & S. stellata & \\
\hline & $\begin{array}{l}\text { Temora discaudata } \\
\text { T. stylifera } \\
\text { T turbinata }\end{array}$ & $\begin{array}{l}\text { Harpacticoida } \\
\text { Clytemnestra scutellata } \\
\text { C. rostrata } \\
\text { Macrosetella gracilis } \\
\text { Miracia efferata }\end{array}$ & \\
\hline & \multicolumn{2}{|c|}{ Chaetognatha } & \\
\hline & Sagitta bipunctata & S. robusta & \\
\hline & S. ferox & S. neglecta & \\
\hline
\end{tabular}

patches are regarded as components of zooplankton communities closely related to the Kuroshio current. Thus, a change was investigated in the composition of the neritic species category with an increase in prey density (Fig. 5). The values presented in Fig. 5 were also expressed as averages of sampling months, as mentioned above. In the low prey density range of $<1000 \mathrm{~m}^{-3}$, most of the species detected such as Paracalanus parvus, $P$. elegans, $P$. nudus, Oithona nana, $O$. simplex, Oncaea media and Microsetella norvegica were similarly abundant. In contrast, with an increase in prey density, 2 species, $O$. media and $M$. norvegica, exhibited a striking increase, and in the patches these species overwhelmingly dominated the neritic category. The relationships between densities of each of these 2 species and those of the sum of the Kuroshio species are shown in Fig. 6 . The densities of 0 . media were positively correlated with those of Kuroshio spe- 

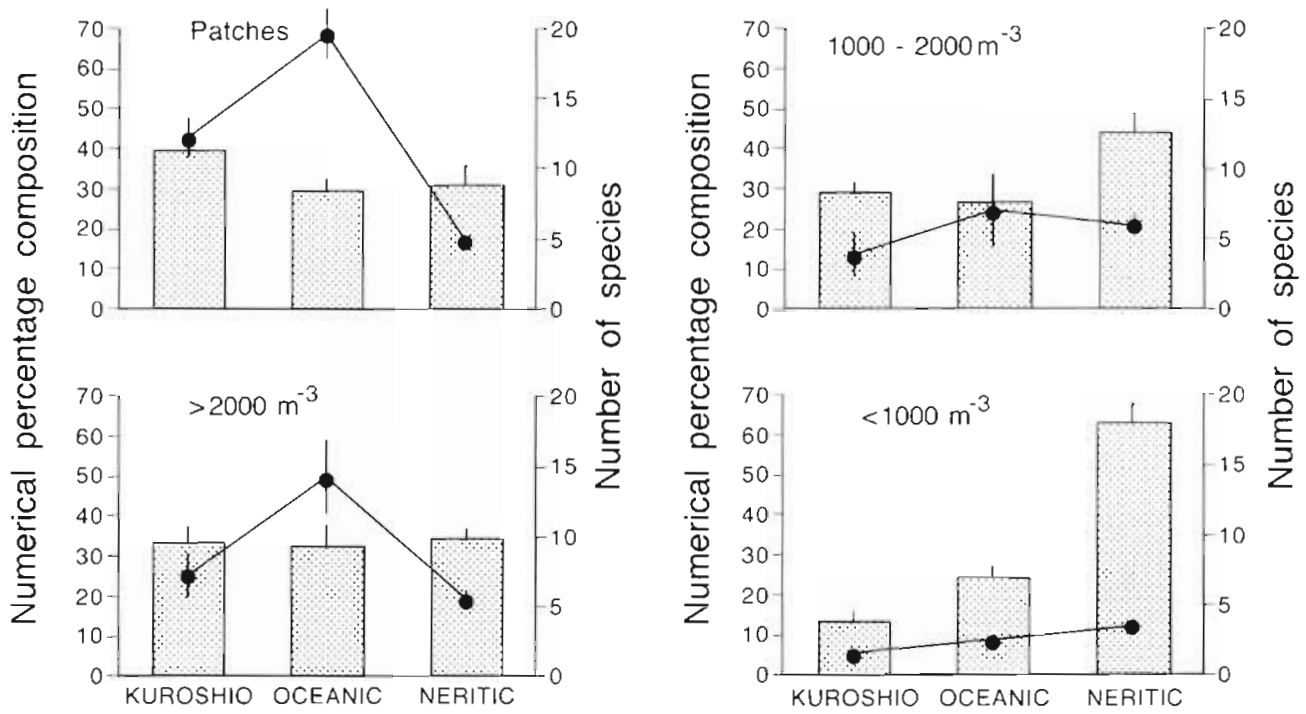

Fig. 4. Comparison of mean numerical percentage composition ( 9 ) and mean species number ( - -) for copepods and chaetognaths between routine samples (assigned to 3 classes based on prey densities of planktivorous fish) and patches with respect to 3 categories represented as indicators of water conditions (see the text). Vertical bars represent $1 \mathrm{SE}$

cies (Kendall's coefficient of rank correlation, $\tau=0.74$ $\mathrm{n}=100, \mathrm{p}<0.001$ ), as were the densities of $M$. norvegica (Kendall's coefficient of rank correlation, $\tau=$ $0.60, \mathrm{n}=100, \mathrm{p}<0.001$ ). In addition, the densities of $\mathrm{O}$. media in the patches were remarkably high (median $1077 \mathrm{~m}^{-3}$, quartile deviation $327 \mathrm{~m}^{-3}$, range 197 to $18795 \mathrm{~m}^{-3}, \mathrm{n}=18$ ), and those of $M$. norvegica also exhibited high values (median $478 \mathrm{~m}^{-3}$, quartile deviation $1047 \mathrm{~m}^{-3}$, range 0 to $5097 \mathrm{~m}^{-3}, \mathrm{n}=18$ ). These results suggest that both species can live and propagate in the Kuroshio water.

\section{DISCUSSION}

\section{Primary mechanism responsible for patch formation}

Recent studies on zooplankton have shown that biological factors such as social active schooling, reproductive aggregation of young due to spawning activity of adults, and coactive aggregation for trophic interactions contribute greatly to patchiness (e.g. Hamner \& Carlton 1979, Haury \& Weibe 1982, Davis et al. 1992, Larson 1992). Although such biological factors may
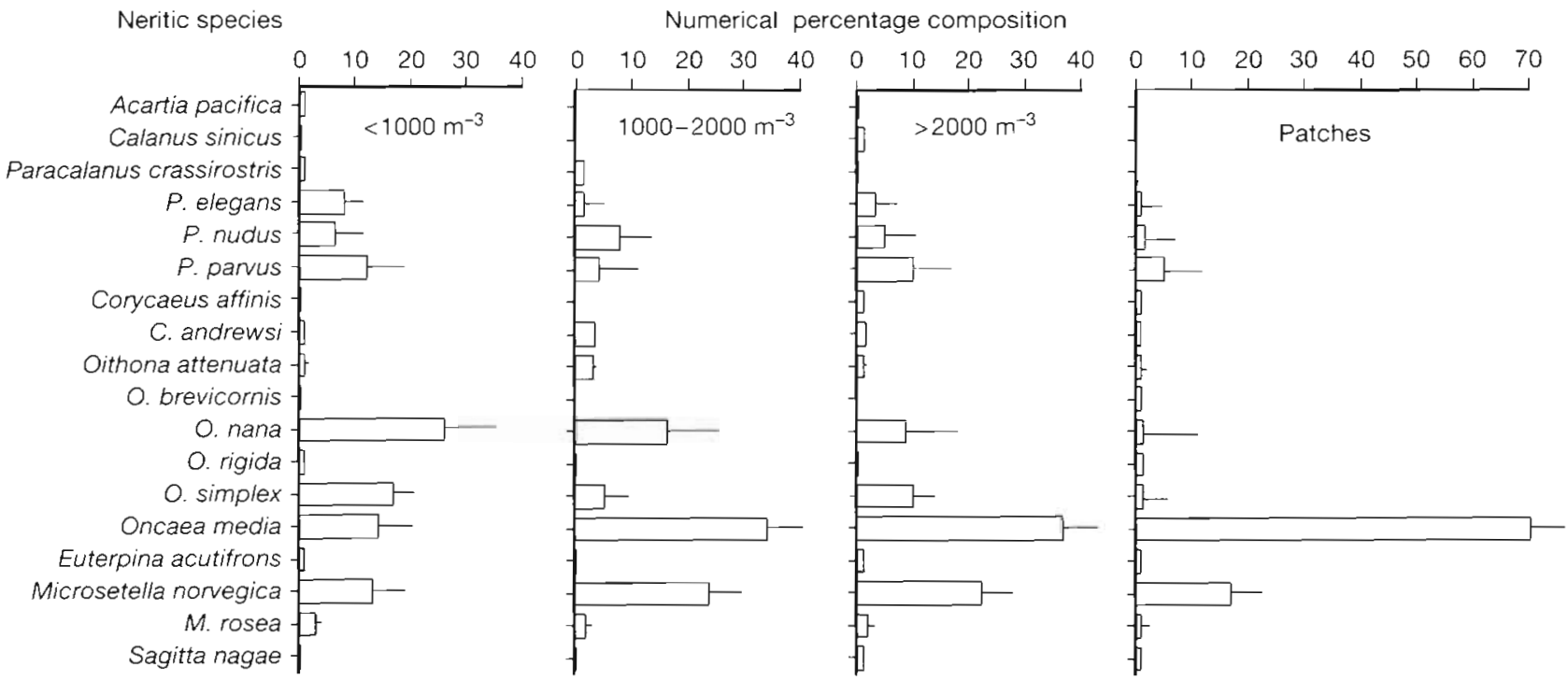

Fig. 5. Comparison of numerical percentage composition of neritic species between routine samples (assigned to 3 classes based on prey densities of planktivorous fish) and patches. Vertical bars represent 1 SE 


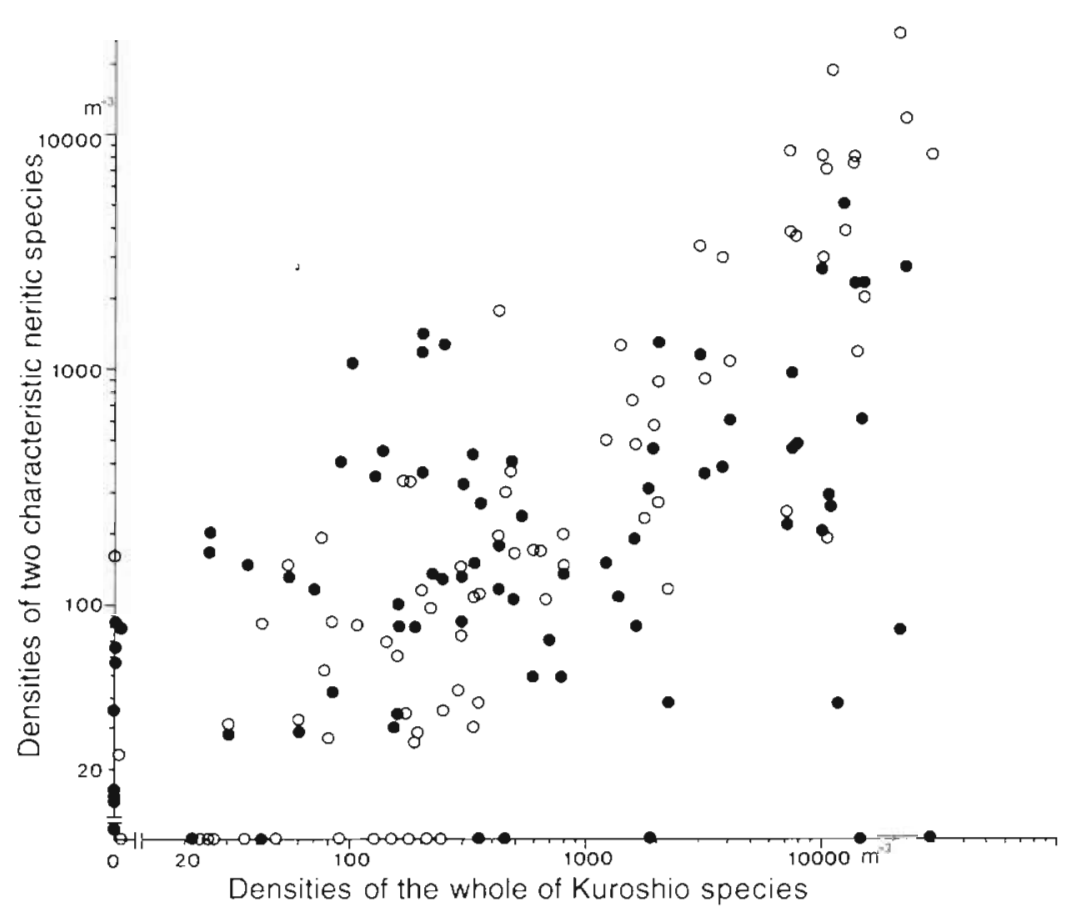

Fig. 6. Relationships between densities of the whole of Kuroshio species and those of 2 characteristic neritic species. ( Oncaea media, (O) Microsetella norvegica. Note log scale

cumulative species composition of routine samples were extremely low despite comparison among samples collected in the same month. Thus they do not depend on streaks.

The results of this study show that zooplankton community structures in the patches are dominated by species which are usually found in the Kuroshio front formed in open sea environments. Copepods and chaetognaths in the patches exhibited no seasonality in species composition and were largely oceanic forms regarded as useful indicators of the Kuroshio water. Such characteristics can be explained by the aggregation mechanism of zooplankton based on the Kuroshio front. In fact, it has been confirmed that zooplankton were strongly aggregated in its frontal region (Yamamoto \& Nishizawa 1986). Additionally, it has been demonstrated that the warm Kuroshio water associated with the short-term fluctuations of the front intruded into coastal areas intermittently within a 20 to $30 \mathrm{~d}$

also operate on the patches analyzed in the present study, the patch formation is difficult to explain only by biological processes. This is because the patches included chaetognaths and copepods in great variety as well as in great abundance despite extremely finescale net samplings (the volumes filtered in patch samples: $0.24 \pm 0.09 \mathrm{SD} \mathrm{m}^{-3}$ ). We believe the patches are primarily formed by physical processes such as accumulation. Hydrographic processes accompanying convergence zones on the sea surface are well known to accumulate debris and pelagic organisms. According to Yanagi (1987), the mechanism of generation of convergence on the sea surface can be divided into 2 main cases: surface convergence within the same water mass, referred to as a streak, and surface convergence between 2 water masses with different properties, referred to as a front. Streaks are generated by physical processes such as a current with a rapid change of coastal geometry, Langmuir circulation and internal waves, and fronts are generated by physical processes such as tidal fronts, coastal upwelling fronts and open sea fronts. If streaks produce the patches at Kuchinoerabu Island, their species composition of copepods and chaetognaths should be essentially similar to the cumulative species composition of the usual background community, owing to convergence within the same water mass. However, in fact, the degrees of similarity between patches and the period (Nagata \& Takeshita 1985, Akiyama \& Ameya 1991). We infer that zooplankton aggregations produced in the frontal area were probably transported into the study site by the intrusion of the Kuroshio water.

Furthermore, the community of copepods in the patches was characterized by 2 dominant neritic forms, Oncaea media and Microsetella norvegica. They are regarded as indicators of inlet waters. It has been shown that in phytoplankton communities at the Kuroshio front formed in the Sanriku waters off northeast Japan, exogenous neritic forms propagated in the frontal area and a peculiar community appeared that was different from those of the 2 conflicting water masses (Yamamoto et al. 1981, 1988, Yamamoto 1989). This is assumed to be due to physical processes, as the Kuroshio current usually entrained coastal waters into its frontal area, and its intense flow generated local upwellings induced by frontal eddies in a shear zone. Similarly, around the Tokara strait, the entrainment of coastal water and the formation of frontal eddies are indicated relative to the short-term variations of the Kuroshio front (Akiyama \& Ameya 1991, Miyaji 1991). Information is not available about whether or not $O$. media and $M$. norvegica propagate in the frontal region though it was reported that aggregations of several neritic zooplankters were distributed in the frontal region (Yamamoto \& Nishizawa 1986, Terazaki 
1992. Nishikawa et al. 1995). However, some aspects suggest that the 2 species have the potential to propagate successfully in the frontal region as well. Generally, $O$. media and $M$. norvegica are distributed widely not only in the inlet or coastal water but also in the oceanic water, and they are most abundant in the admixture of the inlet water with the oceanic water (Yamazi 1956, Hirota 1969a, Hirota \& Hara 1975, Ueda 1982, Koga 1986). Based on food concentrations and predation pressures, Ueda (1991) proposed new categories for the ecological classification of neritic copepods in relation to their horizontal distribution and classified $M$. norvegica as an 'oligotrophic neritic copepod'. They are adapted to low food concentrations and also occur in oceanic waters where predation pressure is assumed to be relatively low. Further investigation is required to understand the relation of the 2 copepods to the Kuroshio front.

\section{Significance of the Kuroshio front in feeding planktivorous reef fish}

Planktivorous reef fish at Kuchinoerabu Island essentially depended on the patches supplied intermittently by the Kuroshio front because of their usual food deprivation (Noda et al. 1992). This means the dynamics of open ocean physical systems such as the Kuroshio front can influence the quantity of food available to those fish. Thus, the influence of such offshore systems should also be noted in the trophic relations of inshore fish communities.

Considering the Kuroshio front as the source of the patches, the pattern of occurrence patches must be regarded basically as a short-term process rather than a seasonal one. The recognition of such characteristics of the zooplankton prey is essential to understand the adaptive aspects of foraging by planktivorous reef fishes in terms of efficient utilization of the patches. With short-term variations of the front, the patches transported into the habitat of planktivorous fish in the coastal region are assumed to be depleted due to predation by plankton feeders such as fish and invertebrates and lack of tolerance of different environmental conditions. They are also sometimes subject to secondary accumulation and mixing induced by coastal hydrographic processes such as Langmuir circulation and the interaction of tidal currents and topography.

In general the Kuroshio current is composed of unproductive oligotrophic oceanic waters, except for highly productive local zones or areas such as fronts, eddies and upwellings, and the standing crop of copepods in the Kuroshio waters, a predominant taxon of zooplankton, is usually low although the diversity of species of copepods is high (Terazaki 1990). However, the effect of the front on the accumulation and propagation of zooplankters enhances the abundance of prey. Furthermore, the prey resource was naturally characterized by numerous large copepods, preferentially utilized by reef-dwelling planktivores, because a variety of large copepods tend to be distributed widely in the Kuroshio water (Terazaki 1990). Additionally, at Kuchinoerabu Island, reef-dwelling planktivores such as the pomacentrid fish Chromis chrysurus feed on larger copepods and other zooplankters that originate offshore, and their substantial prey resource is the patches (Noda et al. 1990, 1992, 1996). Thus, we infer that the Kuroshio front plays an important role in supplying reef-dwelling planktivores with their main prey resource.

Acknowledgements. We are grateful to Dr S. Ohtsuka of Hiroshima University, for identification of zooplankton, Dr F. M. D'Itri of Michigan State University, for his editing assistance and to the people of Kuchinoerabu Island, for permission to work in their waters.

\section{LITERATURE CITED}

Akiyama H, Ameya T (1991) Variation in the Kuroshio front around the Tokara Strait. Umi to Sora 67:113-132 (in Japanese with English abstract)

Alvarino A (1967) The Chaetognatha of the NAGA expedition (1959-1961) in the South China Sea and the Gulf of Thailand. I. Systematics. NAGA Rep 4:1-197

Chen QC, Shen CJ (1974) The pelagic copepods of the South China Sea II. Studia Mar Sin 9:125-137 (in Chinese with English abstract)

Chen QC, Zhang SZ (1965) The planktonic copepods of the Yellow Sea and the East China Sea I. Calanoida. Studia Mar Sin 7:20-204 (in Chinese with English abstract)

Chen QC, Zhang SZ (1974) The planktonic copepods of the South China Sea I. Studia Mar Sin 9:101-124 (in Chinese with English abstract)

Chen QC, Zhang SZ, Zhu CS (1974) On planktonic copepods of the Yellow Sea and the East China Sea II. Cyclopoida and Harpactıcoida. Studia Mar Sin 9:27-100 (in Chinese with English abstract)

Davis CS, Gallager SM, Solow AR (1992) Microaggregations of oceanic plankton observed by towed video microscopy. Science 257:230-232

Furuhashi K (1961) On the distributions of some plankton animals in the Kuroshio region south of Honshu, Japan, with notes on the nature and origin of the cold water mass appearing in the region. Umi to Sora 37:45-59 (in Japanese with English abstract)

Hamner WM, Carlton JH (1979) Copepod swarms: attributes and role in coral reef ecosystems. Limnol Oceanogr 24: $1-14$

Hanaoka F (1972) Some notes on fluctuations of the catch related to the short-term environmental changes in the purse-seine fishing grounds around the Nansei waters. Bull Nansei Natl Fish Res Inst 5:11-24 (in Japanese with English abstract)

Haury LR, Weibe PH (1982) Fine-scale multispecies aggregations of oceanic zooplankton. Deep-Sea Res 29:915-921

Hiromi J (1981) Three species of paracalanid copepods in the 